\title{
КРИПТОВАЛЮТА ИЛИ ЭВОЛЮЦИЯ ДЕНЕГ И ДЕНЕЖНОГО ОБРАЩЕНИЯ
}

\author{
Хаджиев M.P., \\ Эскирханова X.C., \\ Юсупова Т.И.
} ФГБОУ ВО «Чеченский государственный университет», г. Грозный

Модернизация, стремительное расширение денежных рынков, всеобщая автоматизация и совершенствование IT - технологий привели к созданию новых институтов, финансовых инструментов и иных форм взаимоотночений между людьми. Одной из таких форм являются иифровые деньги. В данной статье речь пойдет о цифровых деньгах - криптовалюте и технологии блокчейн. Для понимания роли криптовалюты в эволюиии денег и денежного обращения основным вопросом является определение экономической природы возникновения и механизма работы.

Ключевые слова: биткойн, блокчейн, деньги, криптовалюты, цифровая экономика.

Главным атрибутом финансовой системы и показателем состояния экономики являются деньги. В модели национальной экономики деньги представляют собой инструмент, производственной деятельности товаров и услуг и стимулятор взаимодействия производства и потребления.

Первые упоминания о деньгах появились в 7 веке до н.э. и являлись предметом исследования мыслителей, который окончательно сформировался в отдельную область знаний экономической науки. Однако среди экономистов, по всем основным вопросам денежной теории, не смотря на всеобщую распространенность и многотысячную историю денег, существуют значительные разногласия.

Мировая экономика находится в непрерывном состоянии трансформации: меняются технологические уклады, материальные ценности, механизмы регулирования. Развитие информационных и технологических инноваций послужило к широкому использованию средств шифрования на основе блокчейн технологии, одним из факторов возникновения на этой основе иной формы денег - криптовалют послужил затяжной кризис 2008 года. Субъекты экономики получили возможность проводить финансовые сделки конфиденциально в полной мере оценив возможность работы без посредников. В настоящее время множественные виртуальные криптоплощадки создают свои децентрализованные платежные системы, позволяющие проводить обмен товаров и услуг, тем самым содействуя появлению новых цифровых криптовалют. 
Еще в 90-е годы появились первые идеи по шифрованию операций, связанных с денежными средствами и платежными системами. А вот что касается криптовалюты, этот механизм был технически обоснован в конце 2008 года и 3 января 2009 года, запущена первая децентрализованная платежная система с использованием технологии Blockchain и первая криптовалюта Bitcoin, которая и привела к массовой разработке и возникновению и других криптовалют [11].

Главным отличительным признаком криптовалюты от обычных электронных денег является то, что деньги в электронной форме появляются при непосредственном физическом воздействии.

Для того чтобы денежные средства перешли в электронный вид, их необходимо внести на счет через банк или терминал. Эмиссия криптовалюта же в отличии происходит непосредственно в интернете и не требует извне физического внесения денежных средств, соответственно нет взаимосвязи с реальной валютной системой [10].

Криптовалюта - это цифровые децентрализированные денежные единицы, в основе которых уникальный криптографический код, который представляет собой блокчейн, включающий в себя последовательность блоков (ячеек). В каждой ячейке хранится информация о транзакциях, то есть сделках, которые осуществлялись в сети криптовалюты с определенной монетой. Уникальный криптографический код существует только виртуально, так как криптовалюта не имеет никакого материального аналога.

На сегодняшний день существует большое количество разных видов криптовалют. В настоящее время топ наиболее получивших распространение видов криптовалют представлен следующим образом [5]:

Bitcoin (BTC) - можно определенной уверенностью сказать, что биткойн занимает первое место по популярности, среди криптовалют во всем мире. Частично он признан в качестве актива на государственном уровне во многих странах.

Ethereum (ETH) - является главным конкурентом ВТС с уникальным и отличающимся кодом, разработанным Виталием Бутериным.

Litecoin (LTC) - в 2011 году Чарльзом Ли была запущена криптовалюта с идентичной криптографической системой ВTC, которая обеспечивала аналогичный уровень анонимности и безопасности транзакций.

Dash (DASH) - появившаяся в 2014 году криптовалюта отличалась более высоким уровнем анонимностью и безопасностью, а также меньшими затратами на эмиссию (майнинг) в отличии от ВТС.

Особое внимание при изучении криптовалют и их особенностей уделяется биткоину, который является самой популярной криптовалютой на сегодняшний день. Объем эмиссии биткоинов ограничен, он не должен превышать 21 млн. Уже к началу апреля 2020 года сгенерировано больше 18 млн. ВТС [6]. 
Невозможно дать количественную оценку владельцев биткоинов, связанную $\mathrm{c}$ полной децентрализацией, не подконтрольностью государственным регуляторам и анонимности.

Биткоины функционируют на основе системы блокчейн, которая обеспечивает надежность и безопасность, за счет распределённой системы обработки проходящих транзакций через майнеры, проверяющие достоверность информации, содержащейся в секретных ключах. С увеличением мощностей, генерирующих криптовалюту майнерам требуется уже специальное оборудование в отличии от того периода, когда для этих целей достаточно было обычных компьютеров, либо игровых видеокарт [4, с. 9].

Можно выделить два основных метода майнинга используемые для эмиссии криптовалют: это Proof-of-Work (англ., дословно «подтверждениеработой», сокр. - PoW, пример - Bitcoin) и Proofof-Stake (англ., дословно «подтверждение-долей», сокр. - PoS, пример - Dash). Их отличие заключается в следующем: в случае с PoW наибольшее вознаграждение получает субъект, обладающий наибольшей вычислительной мощностью, в случае c PoS большее вознаграждение получает субъект, обладающий большим балансом криптовалюты.

Изначально идея криптовалюты заключалась в разработке метода расчета, неподвластного государственному контролю, полностью зашифрованного, осуществляющегося быстро и с минимальными комиссиями. При этом абсолютно прозрачного. С учетом незначительных корректировок, это удалось. Цифровые деньги, количество которых с каждым днем увеличивается, не имеют центрального хранилища. Кошелек разделен длинных числа, одно из которых открыто, а второе закрыто. Анонимность обеспечивается за счет изменения идентификатора для каждой транзакции. Все сделки подлежат учету, и любому пользователю предоставляется информация о количестве полученных или отправленных единицах криптовалюты. Вместе с тем, невозможно узнать отправителя и получателя [9, с. 58].

Криптовалюты стали первой массовой апробацией технологии блокчейн, с помощью которой есть возможность выстраивать децентрализованные взаимодействия, гарантируя их защищенность. Это позволяет технологически повысить эффективность экономических отношений исключая посредника, выступающего гарантом выполнения обязательств каждого участника.

Применение криптовалют в денежных отношениях приводит к ослаблению роли государства в регулировании денежно- кредитных отношений и эмиссии денежных знаков, что дает возможность каждому субъекту и обществу в целом контролировать выпуск частных денег.

Криптовалюты имеют ряд характеристик, которые отичают их от фиатных денег и имеют определенные преимущества и недостатки перед ними (рис. 1). 


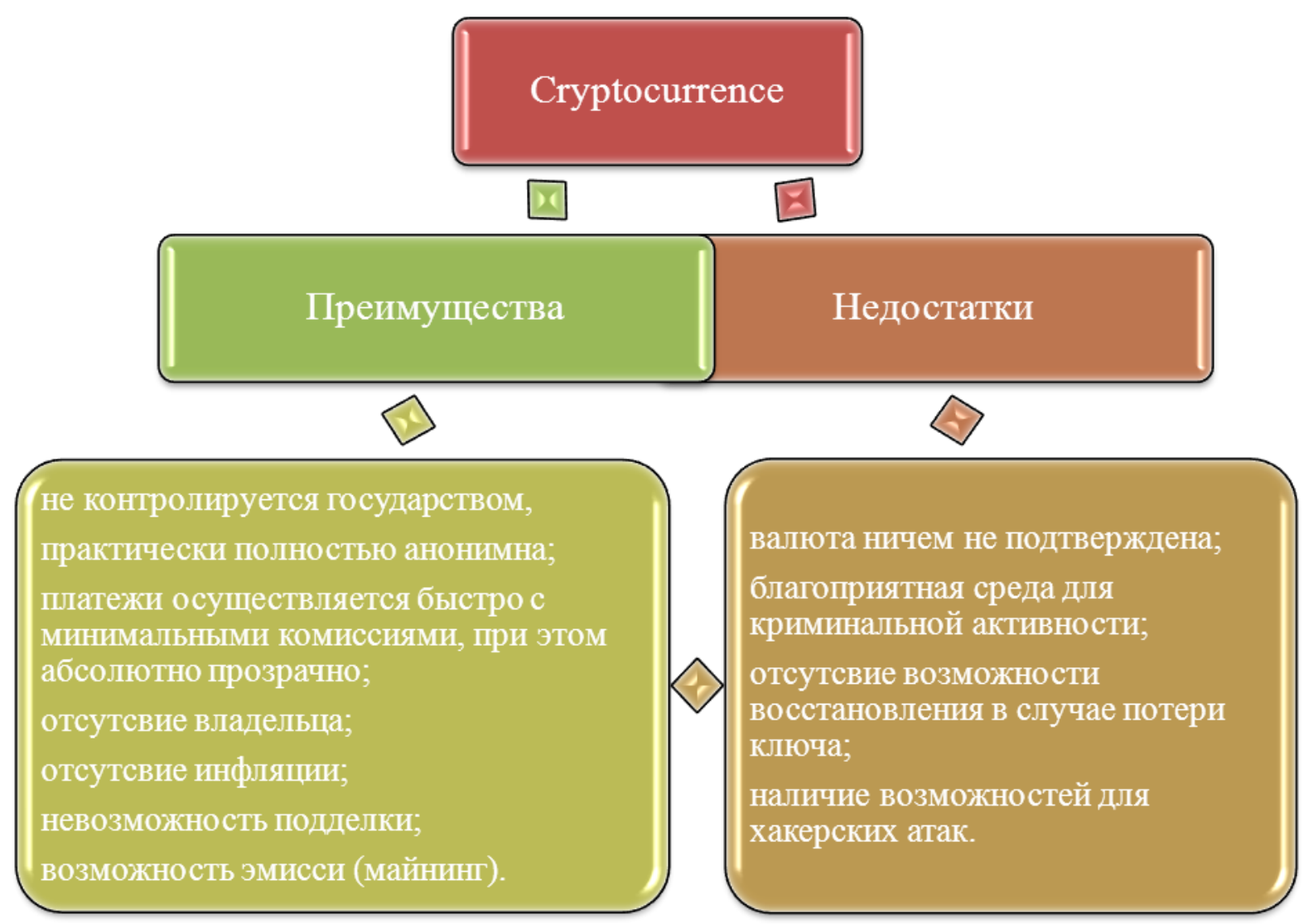

Рис. 2 Отличительные характеристики криптовалют от фиатных денег

На ряду с преимуществами перед фиатными деньгами криптовалюты имеют и свои недостатки. Возьмем тот же биткойн. Главным аргументом против нее является то, что, как и любая другая криптовалюта, она ничем не подтверждена. Ценность биткойна определяется тем количеством продавцов, которые имеют намерение обменять свои товары и услуги на криптовалюту. А как известно, между спросом и предложением регулярно возникает значительный дисбаланс, да и продавцов готовых к обмену не так уж и много $[4$, c. 98$]$.

Абсолютная анонимность отравителя и получателя платежа создает благоприятный климат для криминальной деятельности. Из-за такой скандальной репутации многие государства не признают биткойн и пытаются взять под государственный контроль.

Цифровой ключ нужно хранить в надежном месте, так как, если его забыть или потерять невозможно будет восстановить содержимое. Все цифровые сбережения будут потеряны. Переводы нужно осуществлять, перепроверив все несколько раз, потому что в случае введения неправильного адреса его так же нереально вернуть.

Можно потерять биткойны из-за хакерских атак. Значительный ущерб пользователям биткойнов наносится хакерами, которые взламывают торговые площадки криптовалют. Виртуальные преступники выманивают биткойны у владельцев используя различные программы и схемы [9, с. 46]. 
Даже имея вид программного кода и ограниченные возможности прямого обмена на товары криптовалюта, тем не менее, используется в роли денег.

Увеличивающийся интерес населения к криптовалюте в большей степени связан с возможностью получения сверхприбыли за счет спекулятивных котировок на вложенные денежные средства, однако, по мнению многих экспертов, децентрализованная платежная система, скорее всего, финансовая пирамида, которой в ближайщее время угрожает кризис [3, с. 143].

Каждый день на криптовалютном рынке происходит что-то новое: мошенничество, взломы, неисправности, падения и подъемы репутации цифровых денег. Но существует ряд проблем, решить которые сложнее всего.

Вопрос, связанный с криптовалютой является более сложным для государства, чем для остальных субъектов экономики. Несмотря на то, что есть большой потенциал для развития финансовых технологий, использование криптовалют, несомненно, снижает возможности регулирования и контроля национальных банков.

Как справедливо отмечает В. А. Вайпан, цифровая экономика сейчас формируется на трех уровнях, которые в своем тесном взаимодействии влияют на жизнь граждан и общества в целом. К таким уровням можно отнести:

- во-первых, рынки и отрасли экономики, где осуществляется непосредственное взаимодействие конкретных субъектов;

- во-вторых, платформы и технологии, где формируются компетенции для развития рынков и отраслей экономики;

- в-третьих, среду, которая создает условия для развития платформ и технологий, и эффективного взаимодействия субъектов рынков и отраслей экономики, и охватывает нормативное регулирование, информационную инфраструктуру, кадры и информационную безопасность [2].

В России на государственном уровне было принято решение о выработке основных понятий в сфере цифровых технологий, которые могут оказать влияние на дальнейшее нормативное регулирование данных отношений. Одним из таких понятий является «криптовалюта», поскольку отсутствие правового регулирования отношений по использованию криптовалюты как средства платежа значительно затрудняет процесс цифровизации экономики в целом. В этой связи одним из основных направлений совершенствования правового регулирования в сфере цифровой экономики является государственное регулирование крипто-валютной деятельности [7].

Все отрасли экономики развитых стран мира начинают интересоваться проблемами правового регулирования криптовалютной деятельности. В первую очередь это отражается на динамике использования биткойна на товарных рынках. В Европе крупные интернет-магазины принимают его как способ оплаты, так, например, в Швейцарии можно оплатить обучение в некоторых университетах, в США можно купить его автомобиль (Tesla), во Франции Правительство недавно признало биткойн как альтернативный способ оплаты банкам [2]. 
На сегодняшний день масштаб использования криптовалют не позволяет сделать достаточно уверенный прогноз относительно ухода от использования фиатных денег в пользу криптовалют, если в качестве сравнения принимать общую капитализацию рынка криптовалют, она пока сильно отстает по объемам в сравнении. Однако необходимо отметить, что технология блокчейн и первый продукт - криптовалюта, уже сегодня являются начальной точкой для дальнейшей трансформации мировой экономики, как и те технологии, которые мы используем и применяем сегодня, когда-то были тихими революциями.

И все же нельзя сказать, что старый мир платежных систем и хранения информации будет «разрушен до основанья», так как не все доверяют новым технологиям, тем более таким мудреным. Вероятнее всего, блокчейн займет определенную нишу и будет мирно уживаться с классическими схемами.

\section{Исследование выполнено при финансовой поддержке РФФИ в рамках научного проекта № 19-310-90035/19.}

\section{Список литературы}

1. Беломытцева О.С. О позиции стран Евросоюза в отношении эмиссии и обращения виртуальных валют. // Проблемы учета и финансов. Национальный исследовательский государственный университет. 2015.-255c.

2. Вайпан В.А. Основы правового регулирования цифровой экономики. // Право и экономика. М.: Юстицинформ, 2017. №11 с. 5-18

3. Деньги. Кредит. Банки: учебник под ред. Жукова В.Ф., 4-е изд. М.: ЮНИТИ, 2016. - 56 с.

4. Иванов В.Н. Информационная технология. Криптографическая защита информации. Процессы формирования и проверки электронной цифровой подписи / В.Н Иванов. М.: Экзамен, 2015. - 152 с.

5. Капитализации криптовалютного Рынка (Динамика криптовалют и основные статистические показатели) / Coinmarketcap. [Электронный pecypc]. URL: http://coinmarketcap.com.

6. Капитализации криптовалютного Рынка (Динамика криптовалют и основные статистические показатели) / Coinmarketcap. [Электронный pecypc]. URL: https://coinmarketcap.com/currencies/bitcoin/.

7. О деятельности по приему платежей физических лиц, осуществляемой платежными агентами [Электронный ресурс]: федер. закон от 03.06.09 N 103Ф3 // СПС Консультант Плюс: Справочная паровая система. - Версия Проф, сетевая. - Электрон. дан. - М. 2005.

8. Об электронной цифровой подписи [Электронный ресурс]: Федеральный закон от 10 января 2012г. N 1-Ф3 // СПС Консультант Плюс: Справочная паровая система. - Версия Проф, сетевая. - Электрон. дан. - М., 2005. 
9. Пшеничников В.В. Появление и распространение сетевых денег на примере виртуальной валюты биткоин / В.В. Пшеничников, А.Н Бичев. - СПб.: Финансовый вестник, 2017. - 97 с.

10. Andy Greenberg Security Covering the worlds of data security, privacy and hacker culture. Crypto Currency. Forbes Media LLC. Apr 20, 2011, 06:00pm / [Электронный ресурc]. - URL: https://www.forbes.com/sites/oracle/2019/03/14/ what-if-you-could-predict-when-your-best-employees-will-move-on/\#2c649561353e

11. Satoshi Nakamoto. Bitcoin: A Peer-to-Peer Electronic Cash System. 2008. [Электронный ресурc]. - URL: https://bitcoin.org/bitcoin.pdf. 